\title{
MELiSSA the minimal biosphere: Human life, waste and refuge in deep space Jeremy Walker ${ }^{a}$ and Céline Granjou ${ }^{b}$
}

Forthcoming in Futures, Special issue 'The politics of anticipation: on knowing and governing environmental Futures', (Eds.) G. Granjou, J.Walker \& J.F. Salazar

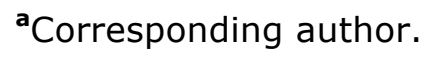

University of Technology Sydney

PO Box 123 Broadway NSW, 2007, Australia

Jeremy.Walker@uts.edu.au

bUniversity of Grenoble-Alps/ IRSTEA, France

IRSTEA Grenoble

2 rue de la Papeterie BP 76

38400 St Martin d'Heres FRANCE

Celine.granjou@irstea.fr

\begin{abstract}
MELiSSA (Micro-Ecological Life Support System Alternative) is a long-term technology program of the European Space Agency. Its aim is to construct autonomous habitats in deep space, supplying astronauts with fresh air, water and food through continuous microbial recycling of human wastes. This article considers how anticipated futures of space travel and environmental survival are materialised in the project to engineer the minimal biosphere capable of reliably sustaining human life: a human/microbe association with the fewest possible species. We locate MELiSSA within a history of bioinfrastructures associated with colonisation projects: refugia in which organisms dislocated from their originary habitats are preserved. Analysis of MELiSSA's sewagecomposting technology suggests that the disordering complexity of human waste presents a formidable "bottle-neck" for the construction of the minimal biosphere, in turn suggesting our dependence on microbial communities (soil, the human gut) of potentially irreducible biocomplexity. MELiSSA researchers think of themselves as pragmatic enablers of space exploration, yet a wider family of space colonisation projects are now imagined in terms of the prospect that the Earth might cease to function as the minimal biosphere capable of supporting civilisation. MELiSSA's politics of anticipation are paradoxical, promising technologies with which to escape from the Earth and through which it may be sustained.
\end{abstract}

\section{Keywords}

Minimal biosphere; Closed Ecological Life Support Systems; space colonisation; waste; sustainable futures.

\section{Highlights}

MELiSSA is a Micro-Ecological Life Support System Alternative orchestrated by the European Space Agency

MELiSSA builds a minimal human/microbe biosphere, a controllable ecosystem with the least possible biodiversity.

MELiSSA anticipates space colonisation both to escape the earth and to conserve it.

Space composting technologies show our vital dependence on a multi-species biosphere. 
The future is shit, just like the past.

- Tyrion Lannister, Game of Thrones Season 5 Episode 1

\section{Introduction}

Our contribution examines how ecological futures are imagined and prepared for through an analysis of the development of artificial life-support ecosystems for space colonisation. A focus on space research may seem an indirect angle with which to analyse the anticipation of dramatic anthropogenic change to the Earth. Yet infrastructures able to sustain human life indefinitely in outer space - refugia - are amongst the technologies called for by scholars advocating preparedness to ensure civilisation endures in the wake of global catastrophes, such as an asteroid impact, or the failure of geo-engineering to contain runaway global warming (Baum et al., 2015).

The human body is adapted to and dependent upon environmental conditions established by the complex relationships between countless organisms through which the Earth has evolved during the 541 million years of the Phanerozoic Eon, the 'recent' third of Earth's bio-geological history, characterised by abundant free oxygen and the existence of multicellular organisms. In 1961, Yuri Gagarin was ejected by rocket from the lifesustaining envelope of the biosphere, becoming the first human to go beyond the earth's gravity well into orbit, in a mission that lasted 108 minutes. To survive every consecutive second spent in outer space, the cosmonaut must be inserted within a life-support system which reliably supplies the vital material conditions of the Earth ordinarily taken for granted - including a thermal envelope not ranging far from the planetary average of $15^{\circ} \mathrm{C}$, air, water, food, and the elimination or neutralisation of wastes. So far, the longest-maintained human habitat beyond the Earth is the International Space Station (ISS). Continually occupied in low-Earth orbit since 2000, the ISS must be re-supplied every few months by rockets from Earth with 'consumables': food and water, oxygen, nitrogen and carbon-dioxide filters to keep the atmosphere breathable, and propellant for the engines that maintain the ISS in its orbit. ${ }^{1}$ Thus far, water purification and the recovery of oxygen from exhaled carbon dioxide has been performed onboard spacecraft via physico-chemical processes. Food has been brought from Earth, and faecal wastes have been ejected into space - destined to become 'shooting stars' burning up on reentry to Earth's atmosphere. Space voyages into deep space, however, will not be able to rely on deliveries from Earth.

The establishment of autonomous human habitats in space demands a biotechnical accomplishment as yet unachieved: the construction of an artificial ecosystem which replicates the atmosphere-stabilising, biochemical recycling, and life regenerating functions of the biosphere at the smallest humanly possible scale. A minimal biosphere enclosed in a vessel: a rigorously anthropocentric ecosystem sealed in a container. Such are the aims of the European Space Agency's MELiSSA project, now testing a prototype of the bioinfrastructure required for the future crewed missions to Mars envisioned in ESA's Aurora Program. ${ }^{2}$ Located within the Department of Chemical, Biological and Environmental Engineering at the Autonomous University of Barcelona, MELiSSA is more precisely characterised as a bio-engineering (rather than an eco-engineering) project. Expertise in biotechnology and chemical engineering inform key technological

\footnotetext{
${ }^{1}$ A key planning metric is the cost to weight ratio of payloads delivered into orbit. Ariane 5 , the ESA's current launch rocket, costs approximately 170 million euros per launch, and can carry 20 tons to low-earth-orbit (LEO), giving an estimated cost of 8,500 euros per Kg delivered to LEO.
} 
development challenges, such as the design of its bioreactors and the genomic characterisation, selection and culturing of the microbiota which are to inhabit them.

In his 'spherological' history of globalisation, the philosopher Peter Slotjerdijk deploys the term 'endosphere' to describe the ship and its interior: the autarkic life-supporting habitat of the sea-faring colonist, a 'mobile homeland' within which to traverse the vast spaces and alien environments of the oceans (2013, Ch. 22). Secure 'endospheres' for human life support will be necessary if space-faring colonists are ever to "escape" from an umbilical dependence on frequent re-supply and replenishment with products of the Earth's biosphere. This problem pre-occupies not only survivalists but also entrepreneurs: it is a crucial stumbling block for deep space exploration, and for projects aiming to expand the frontier of economic activity to asteroids and planetary bodies, in the form of mining, manufacturing, tourism and other ventures.

Thinking through the case of MELiSSA, we consider the paradoxical imaginaries that link technoscientific action toward the the establishment of self-sustaining space colonies to anticipated failures of global ecological processes on Earth in the 'Anthropocene' future.

Our contribution attends to the linkages between space colonisation programs and the globalisation of ecological concern, which the historian Peder Anker describes as a single process of the "ecological colonisation of outer and earthly space" (Anker, 2005). The juncture between space exploration and ecology has proved a fertile ground for the emergence of environmental politics, as shown by the importance of a sub-discipline of ecology, under the name of cabin ecology, in the development of space research in the 1960s. This research would influence the conceptual lexicon of the emerging environmental movement, including the popularisation of the metaphor of the Earth itself as a spaceship (Boulding, 1966). Experiments in cabin ecology, devoted to researching the principles under which human life is possible in complete enclosures for long periods of time, provided models for re-ordering social life to become 'sustainable' within the biophysical limits of the Earth 'system' (Schwarz, 2009). According to Anker, "leading ecologists", including the Odum brothers and James Lovelock, "were investigating how to construct colonies on Mars" (2005, p.239). Illustrative of this convergence is Buckminster Fuller's proposition that "we are all astronauts" in his Operating Manual for Spaceship Earth (1968, p.270), a popular book which would inspire Boulding's economics, and the technocratic systems ecology of H.T. Odum's Environment, Power and Society (1971). 'Earthrise', a photograph taken by the 1968 Apollo mission astronauts of the blue Earth rising over the lifeless lunar horizon, would be the first image to make widely available to the senses the significance of the 'spaceship earth' metaphor by offering a view of the Earth as an isolated, closed vessel sustaining the fragile and probably unique home of life in the universe (Höhler, 2014).

The futures anticipated by the MELiSSA project do not follow the usual line of cleavage between an expansionary frontier politics of technoscientific salvation on one hand, and a self-limiting politics of sustainable regeneration, contained within the system boundaries of the Earth on the other. This dichotomy has characterised environmental debate since the publication of the Limits to Growth report (Meadows et. al, 1972). American economists rejected its logic of finitude, arguing that entrepreneurs would capitalise on scarcity-driven price rises, fostering technological innovations and substitutes for depleted 'natural capital', overcoming limits and continuously expanding production (Solow 1974; Simon 1989). Accepting that mounting depletion and pollution threatened the regenerative capacity of the Earth, others called for a 'steady state' economy, to be 
achieved through 'closed-loop' productions systems in which the waste stream of each industrial process became an input for another, thereby seamlessly re-integrating society's metabolism within the biogeochemical recycling functions of the biosphere (Fischer-Kowalski \& Huttler 1998). MELiSSA's anticipated futures blur this techno-political polarity, exemplifying both sides of the debate simultaneously.

MELiSSA's project to construct a viable ecological 'niche' for human beings in the extremely abiotic and antibiotic conditions of outer space pulls into technological focus the obvious, but often forgotten fact that the minimum unit of life is not the individual organism or species, but the organism-within-its environment, as Bateson (1973: 436) and many others have tried to remind us. It is one thing to acknowledge our interdependence with other biological life, but quite another to design a machine which must internalise these intricately complex interrelations, to engineer a minimal unit of human ecology which must remain functional in utter separation from the Earth.

Drawing on interviews with key MELiSSA scientists, observations of the pilot plant at the Autonomous University of Barcelona, and a reading of the associated scientific literature, we analyze how futures of space conquest are brought into the present form of a minimal socio-ecological organisation within MELiSSA infrastructure. We discuss its material drive to simplify and control ecosystems, and locate this within a history of artificial bioinfrastructures built for colonisation purposes. If this history of infrastructures reveals a trajectory of ever increasing detachment from soil and earth as they foster forms of life uprooted and disconnected from their 'home ground', MELISSA also reaffirms our vital dependence on the life-support bubble of a multi-species biosphere, and the precarious, mutual vulnerability of such a biotic community should its complex regenerative functions be overwhelmed with unassimilable wastes. Tellingly, the most demanding technical problem for MELISSA appears to be in the design of the waste and sewage composting unit of the infrastructure. Our discussion locates this problem of excremental discipline within a broader "biopolitics of shit", whose importance in the production of colonial and post-colonial spaces has been highlighted most recently by Gandy (2014).

\section{Minimal biospheres in space}

In the afterglow of the heroic achievements of the Cold War space race, "visions of constructing entire colonies in orbit or even colonising Mars" were regarded less as science fictions, and increasingly as an "explicitly scientific and widely discussed public program" (Schwarz, 2009 p.134). The US physicist Gerard O'Neill believed that the existing science of the 1970s was sufficient to establish enormous autonomous habitats that would be "richly productive and delightful to live in" (O'Neill, 1976). The scenario for space colonisation presented in his The High Frontier: Human Colonies in Space (1976) was sublimely illustrated, with images of idyllic rural landscapes and chic houses nestled in the curved interiors of huge rotating steel and glass satellites.

Established in 1975, the European Space Agency (ESA) combined previously separate organisations devoted to launcher development and space research established ten years earlier, as Western European governments pooled resources in response to the 'Sputnik shock'. With its headquarters in Paris, ESA is now supported by 21 European states and Canada, with an international staff of about 2000 people and almost 6 billion US dollars annual budget. ESA started programs to develop crewed space expeditions in the 1980s, first in low-Earth orbit, and now, further into outer space. The MELiSSA project began life in 1991, championed by a French engineer, Claude Chipaux, then working in Matra Space 
Branch (today Airbus). After an initial funding application was refused by the French National Center for Spatial Research (CNES), Chipaux pitched the project to ESA, which decided to invest in its unusually long-term program of research. Antecedent projects include NASA's Controlled Ecological Life Support System (CELLS), and the Soviet space research facility Bios3, an enclosure operating between 1965 and 1972 which included an algal cultivator, compartments growing wheat or vegetables and a 3-person crew area. Whilst MELiSSA is yet to conduct an enclosure experiment with human crew, it was established contemporaneously with the privately funded Biosphere II project, a spectacularly ambitious facility built in the Arizona desert between 1987 and 1991 . Covering more than one hectare with rain forest, coral reef, desert, savannah and farm biomes, Biosphere II was designed to maintain an atmosphere and enough food for the eight 'bionauts' who were locked inside for two years. Today, about 100 researchers, engineers and technicians in 14 countries are involved in MELiSSA. MELiSSA partners are linked by a memorandum of understanding and funded by ESA contracts or national grants. Funded for 25 years, MELiSSA currently exists in prototype at the Autonomous University of Barcelona. The project works in a quite centralised and hierarchical fashion under ESA's co-ordinating role, including collective meetings of the whole group biannually and official ESA inspections of the pilot plant every two months.

The central design concept, the MELiSSA loop [Fig. 1], has changed very little since it was first outlined in a paper by Mergeay et al. (1988) as a solution to sustained lifesupport in space. Space missions to Mars are envisioned to last more than 2 years: NASA calculates that the outbound and return trips will each take 210 days, with 496 days spent in a habitat on the Martian surface waiting for the precise orbital alignment enabling a return to Earth (or longer, should it be missed by some accident). It will be impractical for astronauts to simply consume stores of pre-packaged oxygen, water and food brought from Earth. Menezes et. al (2015) estimate that during such a mission, a six-person crew would generate total wasteflows of 5,496 kilograms of carbon dioxide, $8,244 \mathrm{~kg}$ of 'urine water', and $12,725 \mathrm{~kg}$ of 'non recycled water'. Potentially lifethreatening waste cannot be allowed to accumulate, nor can potentially life-sustaining material be 'wasted'. Ideally, all of these waste outputs must be revalorised into humanlife-supporting 'inputs'.

In O'Neill's (1978) visionary scenario, the first built space colony would house 10,000 or more self-governing residents, who would manufacture subsequent habitats from raw materials mined from the Moon and the asteroid belt through "pollution free, solar powered industry". Each new habitat would be ten times the size of the previous one, absorbing and enabling population growth independently of the over-populated and overpolluted Earth. Compared to O'Neill's utopianism, which viewed outer space as a "culture medium, [..] rich in matter and energy ripe for exponential growth", MELiSSA's objectives appear modest, constrained by the real technical difficulties of fabricating an artificial biosphere robust and predictable enough to keep a 4-6 person 'society' alive within the strict parameters (launch weight, cabin space, energy supply) of currently viable spacecraft designs.

Toward this end, MELiSSA consists of a succession of bio-reactors harnessing the capacities of selected microbial strains and communities, aiming to achieve a complete and continuous conversion of human wastes into edible biomass, drinking water and breathable air. Unlike the Noah's Ark approach of Biosphere II, MELiSSA does not reconstitute existing biomes in representative miniature, in the hope that 'global equilibrium' will set in spontaneously from the complex mutual adaptation of populations 
of plants, insects, animals and bionauts to one another. Biosphere II seems extravagantly capacious, bio-diverse, and tolerant of unpredictable emergence when compared to the rigorously minimalist community and precision-controlled circulations envisioned by the MELiSSA project. MELiSSA strips out as much biodiversity as possible, reducing its biosphere to the most basic of the microbiological processes that sustain global ecological functions.

MELiSSA's miniaturisation of geomicrobiology is entirely anthropocentric. Parameterised to accommodate only the influxes and outflows of human bodies, this is a human/microbe association in which all the 'open-ended creativity' (Hird, 2009) of complex bio-social communities has been excluded, and from which all unnecessary lifeforms - indeed all multi-celled species but humans and their food-plants - are to be eliminated ${ }^{3}$. Microbial species will not be 'wild' strains, they are modelled, screened, selected, and engineered for their capacity to be reliably 'cultured' to 'work' efficiently and reliably to recover air, edible biomass, and water from human waste-flows. Yet even so, the knowledge required to achieve reliability and control is considerable, as one interviewee noted:

"[W]orking with biological processes and a closed system, [...] you cannot limit yourself to carbon, nitrogen, oxygen [...] because a lot of biological processes depend on trace elements [...] if you don't have these, then the system collapses. Not only do you have to master a high level of characterisation, but almost with a complete Mendeleev [e.g. periodic] table. So, if I were exaggerating, you should have at any time of the cycle a complete Mendeleev formula to know exactly where you are. [...] let's assume [...] somewhere in the loop you accumulate iron on a surface of a material or whatsoever. Then after two or three cycles you have full depletion, the system will collapse."

The MELiSSA Ioop (Picture 1) comprises five compartments colonised respectively by microbiota and edible plants, interconnected by tubes which circulate elements between microenvironments tailored to the species inhabiting them (Lasseur et al., 1996; Godia et al., 2002; Garland, 2007). Compartments II, III and IVa contain pure (axenic) cultures of bacteria - respectively, photoheterotrophic bacteria, nitrifying bacteria, and photosynthetic cyanobacteria (Picture 3) - which are kept rigorously separate, apart from purified inflows and outflows of basic elemental compounds exchanged with other chambers. Compartment IVb is a growth chamber for the higher plants which will supply astronauts with food. 


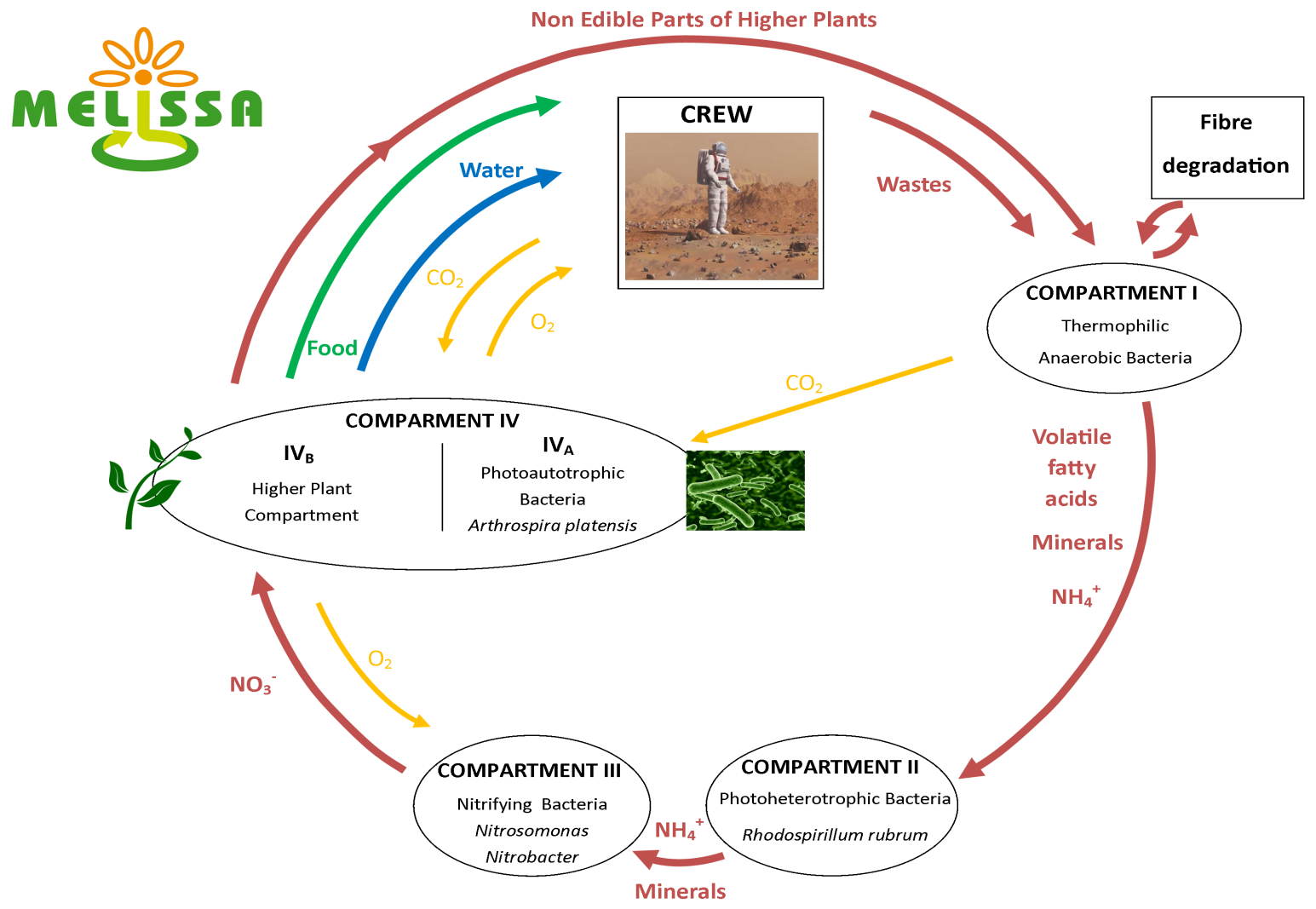

Picture 1: The MELISSA loop. Image courtesy of Christophe Lasseur/ESA @ .

If modeled in principle upon natural aquatic ecosystems such as ponds and lakes (Hendricks and Mergeay, 2007), the pilot plant in Barcelona appears rather like a highly sophisticated tangle of machinery; inside a sterile clean room, stainless steel tanks are connected by various tubes and pipes, the vital flows within carefully monitored and reconditioned by computer. Whilst it is intended to become a closed 'ecosystem', at present a better analogue for MELiSSA might be the pharmaceutical plant: chemical products are manufactured in bioreactors according to rigorous standards of purity, control, predictability and safety. 


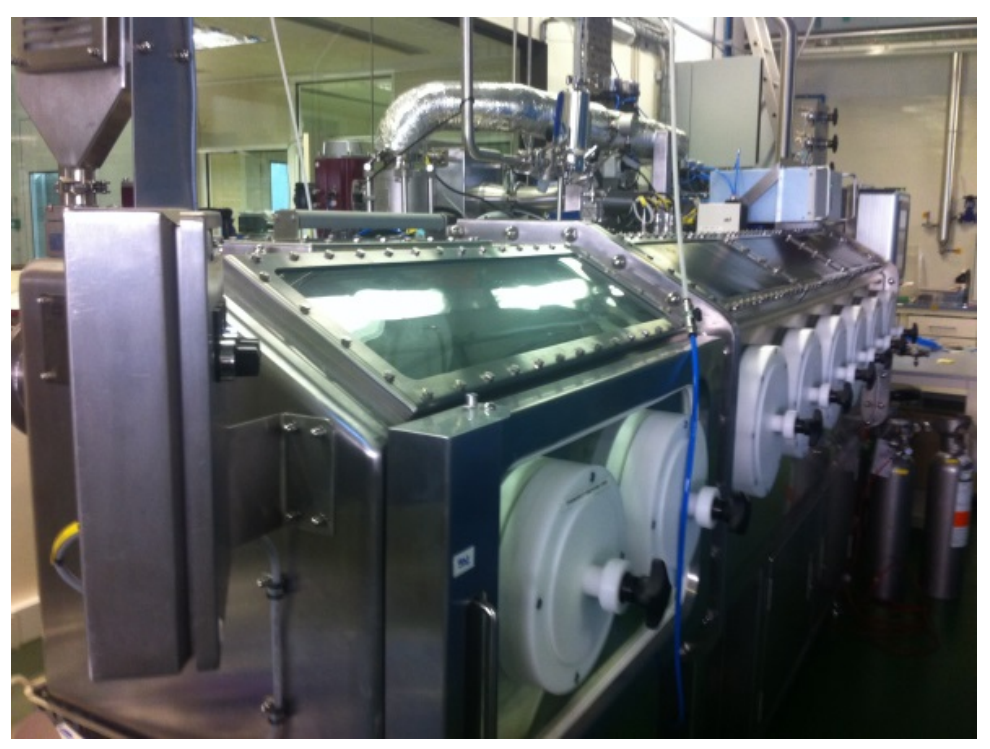

Picture 2- MELiSSA pilot plant (Autonomous University of Barcelona): living quarters of the 'crew'. Currently inhabited by rats. Photographed by authors $\left(25^{\text {th }}\right.$ November 2015)

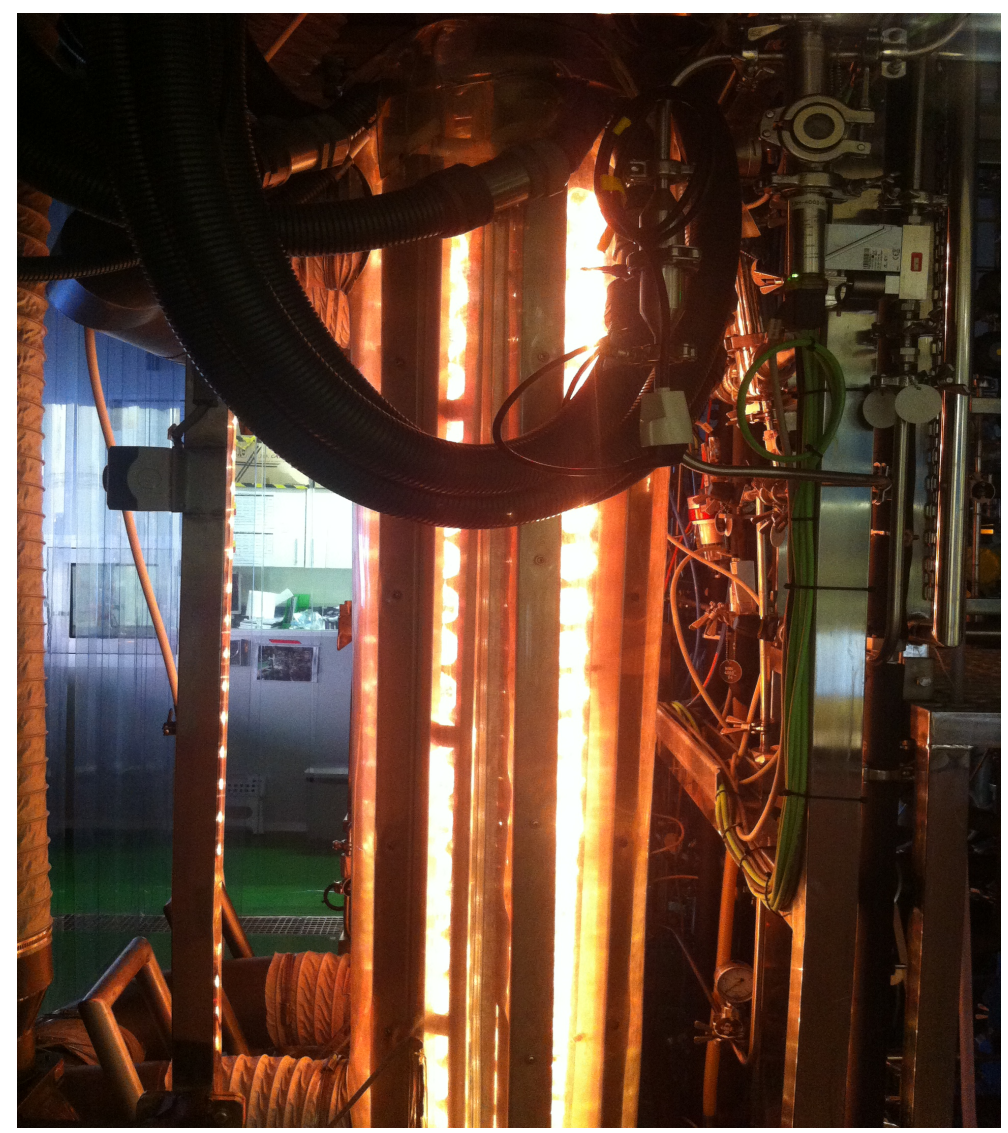

Picture 3- The photosynthesis compartment (IVa). Water and carbon-dioxide inputs are transformed by cyanobacteria of the genus Arthropspira ('spirulina') into oxygen and edible biomass. Photographed by authors $\left(25^{\text {th }}\right.$ November 2015$)$ 


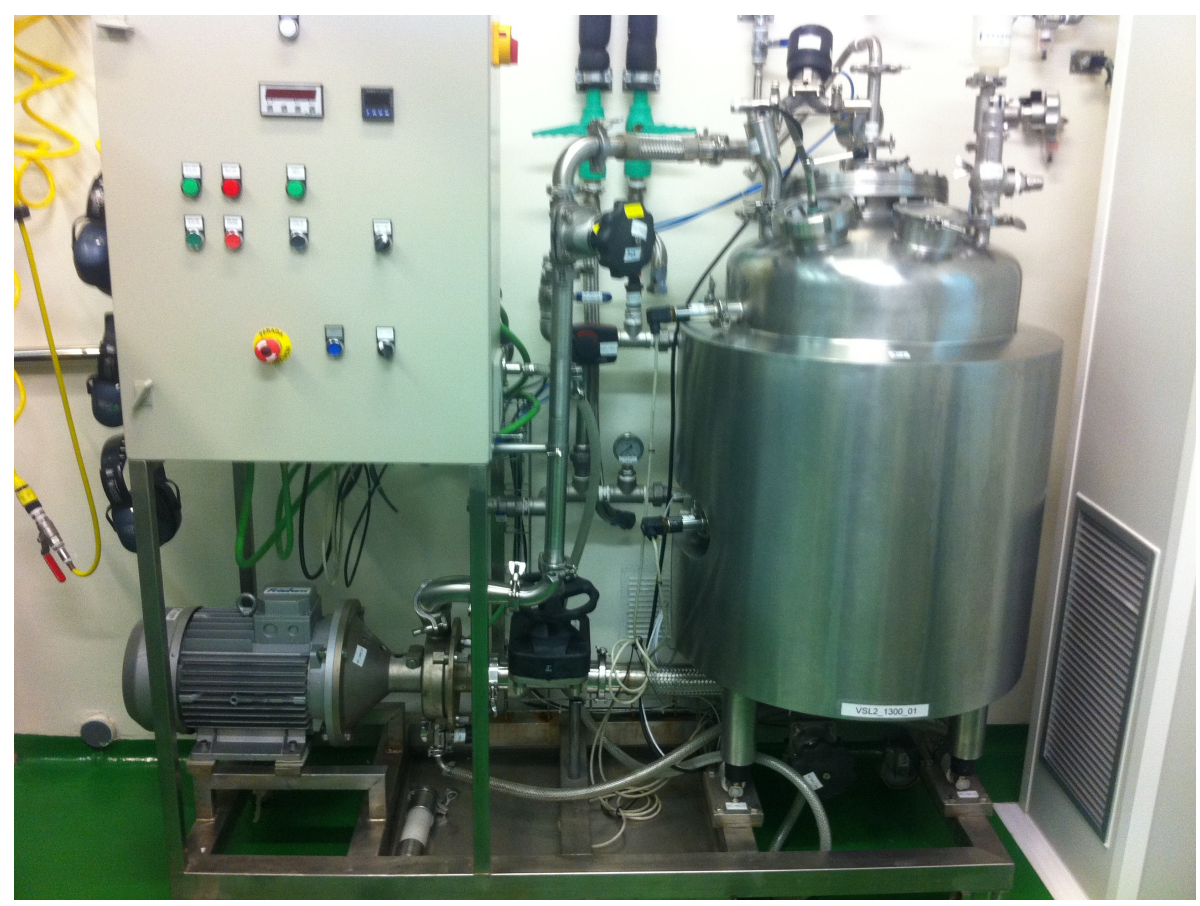

Picture 4 - The composting compartment (I). Complex bacterial communities process human faeces and plant wastes. Photographed by authors ( $25^{\text {th }}$ November 2015

As distinct from the axenic cultures of the other compartments, Compartment 1 (Picture 4), a composting chamber for plant wastes and human faeces, is a far more complex microbial community, containing anaerobic thermophilic bacteria and a multiplicity of microbes endemic to the human gut. Indeed the human body and its waste composter will by the prime refuge of biodiversity on such a mission: researchers on the Human Microbiome Project estimate that around 10,000 microbial species occupy each human ecosystem (NIH, 2012).

It turns out that the biological transformation of human excrement back into vital, valuable bodily inputs is one of the most difficult processes to simplify and stabilise through the reductive techniques of industrial microbiology. Governing the messy complexity and discomfort of proximity to 'shit' (which connects waste-making indelibly to consumption and self-care) is critical for colonisation to continue into the vastness of deep space. The "politics of shit" has been emphasised in colonial and post-colonial contexts by scholars interested in the nexus between the human body, technology and poverty (Anderson, 1995; Appadurai, 2001; Gandy, 2014). It is this foundational biopolitical problem, we argue, that situates MELISSA within the wider history of colonisation and its life-support systems. MELiSSA hybridises a lineage of infrastructures that maintain select organisms in enclosures insulated from local conditions: boundarymaking architectures which delineate life-sustaining, secure interiors from the inhospitable, exteriorised spaces of colonisation.

\section{Refuge and colony: past and future greenhouse geopolitics}

The Latin word 'colonus' signifies the Roman soldier-farmers who 'settled' newly conquered territory; and greenhouses were integral to more modern processes of globalisation and colonisation. MELiSSA's genealogy might be traced back to the jardins 
d'acclimatation that played no small part in the historical economy of globalisation, through the de-localisations and asymmetrical exchanges associated with the colonisation of "new" worlds, and forward to the self-regenerating artificial biospheres that may one day enable colonies in outer space ${ }^{4}$. Obviously, the collections of organisms housed inside the climatic refuges of $19^{\text {th }}$ century greenhouses were selected with very different intentions to those assembled for contemporary space research. In the case of the former, for the aesthetic pleasure of privileged elites, living archives of previously 'uncharted' biological resources were transmitted from the trans-oceanic frontiers of European empire. In contemporary space research, the emphasis is on the experimental sciences of exobiology, bioengineering and systems ecology necessary to assemble reliable life support for a handful of spacefarers. Both are ostensibly motivated by the humanist project of scientific progress, both offer protected habitat for living beings far from their home 'sphere', both are linked to enabling technologies for long distance traffic and the management of remote resources.

The $19^{\text {th }}$ century jardins $d^{\prime}$ acclimatation were then the most sophisticated of greenhouses, 'conservatories' built in the cold climates of metropolitan Europe to sustain collections of plants and animals transported from newly colonised 'torrid zones'. Emperor Napoleon Bonaparte sponsored scientific expeditions of exploration to recently discovered new worlds, and his wife Josephine (1763-1814) played a critical role in the acclimatisation and 'naturalisation' of novel plants and animals from Australasia, Asia, Africa and the Americas. Raised by sugar-planters on the island of Martinique, Josephine was fascinated by exotic plants and flowers. She commissioned a 50 meter long hothouse in the Château de la petite Malmaison, near Paris, to cultivate and display hundreds of exotic plants, such as acacias and eucalypts brought back from Australia by the BaudinPeron expedition of 1800-1804. Malmaison became part of a global network of botanists, zoologists, horticulturalists and agronomists, connecting the Royal Botanic Gardens at Kew (London), the Jardin des Plantes (Paris) and numerous other collections with fieldworkers in the colonies. ${ }^{5}$ A sophisticated system of heating equipment was installed in order to recreate an Antipodean climate for Josephine's deterritorialised organisms, requiring a crew of laborers to continually fuel forty-five furnaces with coal. Such was the expense of maintaining the hothouse, only an Empress could afford it: when Malmaison was later sold, the greenhouse was demolished (Pougetoux, 2012).

By contrast, the monumental complex of Royal Greenhouses at Laeken, built in Brussels between 1873 and 1894 at the behest of King Leopold II of Belgium, remains in operation to this day as a private royal garden only occasionally opened to public viewing. Leopold II became fabulously wealthy as the personal ruler of the Congo Free State (1885-1908), the ultimate beneficiary of the genocidal mobilisation of the population of a land roughly the sise of Western Europe into forced labour for the rubber and ivory commodity booms. Estimates of the number of people killed during his tenure range from 2 to 15 million. It was said of Leopold II, who never visited his fiefdom in Congo, that "flowers were poetry for him and were for him a revenge against the exigencies of reality". Enclosing "a tropical landscape of hitherto unattained sise and abundance of flora", an imposing glass city of "megalomaniac dimensions" was commissioned (Kohlmaier \& Von Sartory, 1986: 208-209). The crystal pavilions span 5

${ }^{4}$ For a more detailed genealogy of artificial biospheres in the context of the history of functional ecology see Granjou and Walker (2016). 
acres of floor-space, and require the combustion of 800,000 litres of fuel oil annually to maintain their climate-controlled microcosms.

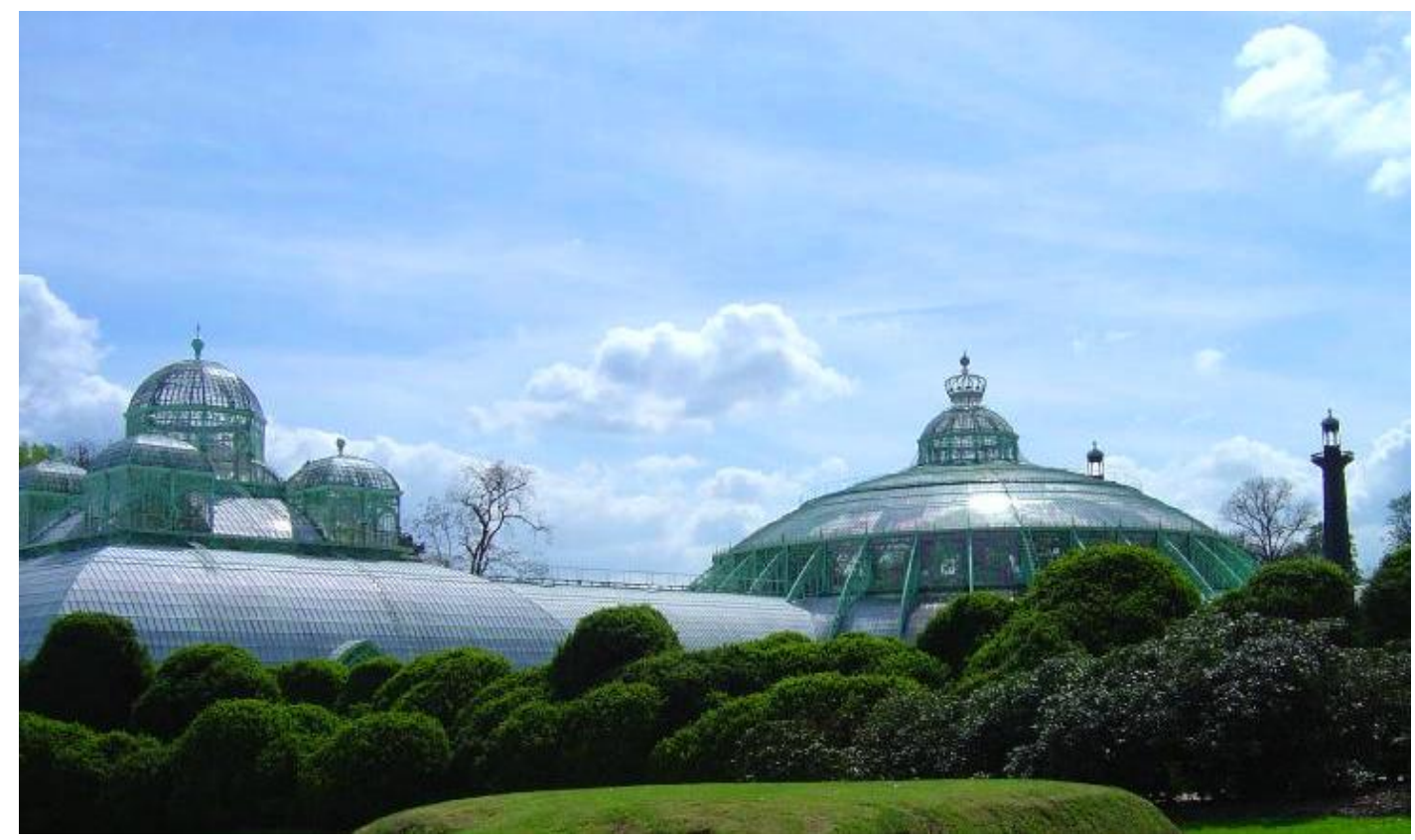

Picture 5- The Serre du Congo (left) and the Grand Jardin d'hiver (right), part of the Royal Greenhouses of Laeken. Source: Joris Van Grieken, Public Domain, Wikimedia Commons

According to a recent projection (Akkermans et. al 2013), as a result of greenhouse gas emissions, by 2050 the climate of Congo will be on average $1.4^{\circ} \mathrm{C}$ hotter than now, with the local effect of anticipated levels of deforestation potentially adding an extra $0.7^{\circ} \mathrm{C}$ to that figure regionally. Loss of rainfall, thermal stress, and intensified wildfire regimes are already threatening to make rainforests potentially 'homeless' in many of the bioregions they have long dominated. For many endangered species, evasion of complete extinction may only be likely in vitro, as refugees granted 'biosecurity' in zoos, biodiversity banks, and rare botanical collections such as the Serre du Congo (Picture 5)

Since the late 1990s, the Congo has been overwhelmed by episodes of extreme violence comparable to the Belgian era, which has again been accorded little concern in the political discourse of the international community. Observers have attributed the violent environments of the Congo to a resource war, as mining companies aligned with rebel militias or border-crossing militaries compete to exploit rare mineral resources, often through slave labour. Oona King, a British parliamentarian, has concisely summarised the bio-geo-politics of contemporary Congo: speaking of surging demand for 'coltan' (columbium tantalite), a metal indispensable for the production of cell phones, laptops, Playstations, and the electronics of spacecraft (Montague, 2002), she observed that "kids in Congo were being sent down mines to die, so that kids in Europe and America could kill imaginary aliens in their living room" (Hari, 2006).

The lineage from the imperial greenhouse to the recent resuscitation of the space race, driven by visions of mining asteroids, or terraforming Mars, may not be obvious. Certainly we would not want to imply bad conscience to ESA's space scientists, nor to 
insist that "there is no document of civilisation which is not at the same time a document of barbarism" (Walter Benjamin). Yet these habitat structures for ideally ordered 'minimal communities' share the utopian feature of being a 'good place' that is radically displaced (Utopia $=$ no place). Built for biological survival in inhospitable environments, for conserving and disseminating life to alien spaces, in vitro biospheres play their part in the globalisation of what Slotjerdijk (2013) describes as 'the world interior of capital': inside, the winners of globalisation are secured in climate-controlled habitats and vehicles, whilst the losers are kept outside the glass in increasingly hot, hazardous and chaotic worlds.

Artificial eco-spheres are thus boundary objects par excellence in Judith Butler's sense, embodying the kind of exclusionary biopolitics suggested by the philosopher:

"What constitutes through division the "inner" and "outer" worlds of the subject is a border and boundary tenuously maintained for the purposes of social regulation and control. The boundary between the inner and outer is confounded by those excremental passages in which the inner effectively becomes outer, and this excreting function becomes, as it were, the model by which other forms of identitydifferentiation are accomplished. In effect, this is the mode by which Others become shit" (Butler, 2010, p.182).

The exploitation of the New World and the colonisation of Outer Space might be said to represent two versions of a utopia of infinite exploitation. In the former, surplus lives can be wasted at a distance, without the political consequences coming home. In the latter, the (likely) complete absence in space of life and history ensures that resource exploitation may proceed in a purely instrumental fashion: this time, it is hoped, with clean conscience. Deep space pioneers will have no one else to deal with their shit, and no-one else's shit to deal with but their own. One must become one's own shit: remaining alive depends on it.

\section{4- Composting sans soil, sans worms, sans emergence}

The genealogy from Malmaison to MELiSSA exhibits a trajectory of life's dislocation from its prior rootedness in ground, soil and earth: an increasing "de-grounding" and deterritorialisation of select multi-species communities, and an increasing dependence upon the technological conditions provided within the synthetic biosphere. MELiSSA aims to take a giant leap further in the de-territorialisation of human ecology, designing a system of nutrition and waste transformation for conditions of complete disconnection from place, earth and soil.

Unlike the imperial greenhouses, Biosphere II, and other experiments in CELSS engineering, plants are not grown in something approximating terrestrial soil. An experiment with lettuces was underway when we visited the pilot plant in Barcelona, their roots in a hydroponic system which circulates nutrient enriched water (Paradiso et al., 2013). Lettuces were grown on a slow moving conveyor which carries them toward the end of the growth chamber as they mature. Plant growth generates oxygen as well as food. Germination is staggered sequentially in order that oxygen levels are stabilised over time, as well as food harvesting. It is planned that nearly 20 different plants will be grown in the final MELiSSA infrastructure, invoking the possibility of undoing our dependence upon earthly soils, which have been progressively depleted of nutrients by intensive commercial agriculture - a phenomenon which biochemist Justus von Liebig 
first raised the alarm on in the mid- $19^{\text {th }}$ century. Given the toxicity of Martian soils, MELiSSA prepares for sustainable agricultural practices without soil or synthetic agrochemicals.

Plant nutrients are provided in MELiSSA by circulating the liquid byproducts of microbial metabolism within the composting part of the infrastructure, which centrifuges and transforms the plant wastes, human wastes and toilet paper into carbon, nitrogen, phosphorus and other elements. Strikingly, while the microbial communities in other compartments of the MELiSSA loop are axenic - pure strains cultivated in secure isolation from any contamination - in the composting compartment of MELiSSA is it impossible to use a pure microbial strain. Instead, the microbes present in the composting machine are introduced from the human gut and cultivated and adapted to the type of waste which scientists and engineers anticipate will be produced in the spaceship (Hendricks et al., 2006). The culturing of pure strains for compartments II, III, an IVb occurs in parallel with the attempts to model and stabilise the "natural" microbial associations that develop in the composting chamber, which - supplied with human faeces by ESA volunteers involve multiple microbial taxa that resist laboratory culturing techniques, and whose functional properties thus cannot yet be precisely characterised, although the methods of environmental genomics are being applied to this task. The outputs of the composting machinery will be needed as nutrients to be fed into the other compartments for air and food production, but at present the composting machinery is not yet connected to the plant growth chambers of the Barcelona pilot plant.

Colonised by the microbiome of the human gut, the composting compartment represents the most ecologically complex sample of the Earth's biosphere in the MELiSSA pilot. Inserted into the dark interior of the composting chamber, human "night soil" represents an opaque matrix of earth and its vital multispecies interdependences. Puig dela Bellacasa (2013) describes soil as "bioinfrastructure", accounting for the invisible yet vital role fulfilled by soil's microbial labour in sustaining all biological and social existence. In MELiSSA, an earthless microbial "bioinfrastructure" has been re-composed and reconditioned to human purposes as microbial labour is systematically monitored, conditioned and re-engineered in order to fulfill the recycling role of soil - without soil. This yet this minimalist, functionalist proxy for soil still reaffirms our vital dependence on the biosocial order of a multi-species biosphere - and the precarious vulnerability of the whole community, should its complex bio-regenerative processes become undernourished, or overwhelmed by unassimilable pollution.

Composting is increasingly adopted by urban households concerned with food security and sustainability. Abrahamson and Bertoni (2014) have written on the vermicompostor, a wooden or metal box designed to fit even the smallest city flat. Kitchen scraps are fed to a community of worms housed in the unit, which secretes a nutrient-rich fluid, an ideal plant fertiliser. They note that for this sustainability technology to succeed, the multispecies community it instantiates (humans and plants interacting with the worms, fungi, and microbes inhabiting the composter) must learn to live together. Appropriate worm-food must be punctually supplied to the vermicomposter if it to digest and decompose the waste properly; rebellious worms tend to escape from the box and invade the kitchen if they are not fed properly. Learning to co-habit with companion species involves adopting mutual habits of sharing food and space - here we are reminded of the origin of the term "companion", which means in Latin sharing (com-) bread (pane) (Haraway, 2008 p. 15). Of course, kitchen compost units are not ordinarily expected to process human faecal matter. 
Far from the congenial multispecies learning described by Abrahamson and Bertoni, MELiSSA aims to extend control over a composting process from which unexpected events are to be eliminated, and to which no self-respecting earthworm would be party. As waste circulates in the machinery, two redundant circuits are set up in order to avoid any failure of the composting process: should the initial circuit block and fail, it would be automatically replaced by the twin circuit during the repair time. Here, kitchen garden composting is not only to be combined with sewerage treatment, but integrated with biomedical practices developed in the context of pharmaceutical production and hospital intensive care units: everything is precisely controlled and carefully monitored to ensure a final biological product: human survival.

The necessity of recycling human waste has been asserted by a long line of scientific reformers of agriculture since the globalisation of soil depletion became clear in the mid19th century to the pioneering soil scientist Justus von Liebig. For von Liebig, Chinese agriculture was "the most perfect in the world" because of its careful management of "the most important of all manures", the human excrement that was collected from individual houses and used to fertilise surrounding fields (Liebig, 1852, pp. 65-66 in Wilson, 2010). Liebig was a contemporary of the Irish engineer Jasper Wheelers Rogers, who argued for the industrial treatment and re-use of human excrement - at the time provoking epidemics of cholera in London due to an inadequate sewerage system. Transferred from farmland to urban waterways, nitrogen and phosphorous were being depleted from croplands no longer fallowed or enriched by stubble burning, nor replenished with human and animal wastes. Local soil depletion drove colonial powers to a global project of 'guano imperialism', seizing islands and cays long-inhabited by seabirds and evicting them (along with indigenous people, as in the case of Nauru), to exploit rich deposits of this natural fertiliser (Saito, 2014). Liebig's vision of the return of urban wastes to the soils that supported urban populations was not to be realised at the scale of the problem: increasingly sophisticated sewerage systems transported sewage further away from residential areas; and as the agro-chemical industries developed, synthetic fertilisers enhanced the economies of scale of mass mono-crops, further globalising the 'metabolic rift' (Foster \& Magdoff, 1998).

A century and a half later, MELiSSA revives von Liebig's ambition to recycle accumulated human waste in a self-sustaining agricultural system instead of "wasting" it, or pumping it out to sea in accordance with the doctrine that the solution for pollution is dilution. MELiSSA may thus be said to open a new chapter in the subterranean "history of shit", a study inaugurated by the radical philosopher Dominique Laporte (1978), who argued that all civilisation ultimately resolves to the more or less sophisticated character of its sewage facilities. This approach is productively employed in Gandy's (2014) history of the spatial hierarchies generated by the hydraulic infrastructures that channel drinking water, waste, and floods throughout the hygienic suburbs and peripheral slums of modern megacities, from Lagos to Mumbai. An earlier history of colonial urbanism is told by Warwick Anderson (1995), who suggests that the Western quest for cleanliness, isolation and purification through governmental and hydraulic systems which rendered invisible the traditional act of outdoor defecation, was paradoxically the cause of closer proximity between the sites where people live, eat, do business and defecate, as toilets were progressively located inside houses and new waste treatment technologies became available. Anderson emphasises how urban power operated through an "excremental colonialism" which policed the mandatory building of toilets in indigenous houses through racial categories. MELiSSA's brief, life support for remote space expeditions, demands an 
unprecedented disciplining of excremental habits and flows, introducing a claustrophobic proximity between the crew and its wastes.

Understandably then, MELiSSA's infrastructuring environment must embody the strictest purification, sterility and isolation protocols (stainless walls of composter tank and pipes, strictly closed caps and connections, micro-filters and sensors, bioreactors kept separate from humans in clean-rooms). Leakages and potentially contaminating mutual encounters between the inhabitants of the composting compartment and the rest of the infrastructure could be fatal. The crew must live in spatial proximity with waste processes, intimately integrated within closed loops of re-circulating fluids driven by high-precision hydraulic equipment and the transformative biochemical pathways of microbial organisms ensuring the complete, continuous and punctual transformation of today's shit back into tomorrow's food. The goal is to achieve $100 \%$ recycling of human waste, but experience suggests the difficulty of avoiding all contamination and mixture. An experiment carried out at NASA's Langley research center in the early 1960s, in which a 'crew' of four men were enclosed within a bio-infrastructure called the "NASA Living Pod", was prematurely terminated after four months. Despite careful practices of waste collection, human hair, fingernails and skin cells infiltrated and contaminated the system causing headaches and nausea (Kallipoliti, 2008).

\section{5- Conclusion}

The futures anticipated by MELiSSA emerge out of a complex lineage of encounters between colonisation and sustainability, endlessness and scarcity of space and resources, purity and contamination. Astrid Schwarz argues for a historical shift from a heroic conception of cabin ecology "being ready to explore outer space, spread plentiful resources and build new biospheres", to the sobering realism of 1970 s systems ecology, in which "the concept of carrying capacity is extended to encompass Spaceship Earth so that all resources, including space, are scarce" (Schwarz, 2009, p.138). Our study suggests that both conceptions and imaginaries are simultaneously at play in MELiSSA's imagined futures.

Paradoxically, MELiSSA advances space research in order to live beyond the Earth, and to preserve it - a common argument among space colonisation promoters. MELiSSA researchers think of themselves as pragmatic enablers of space exploration, yet a wider family of space colonisation projects are now imagined in terms of the prospect that the Earth might cease to function as the only biosphere capable of supporting civilisation. Promoters of the Project Persephone aim to build "prototype exovivaria, closed ecosystems inside satellites, to be maintained from Earth telebotically and democratically governed by a global community" (in Hamilton, 2014, p.12). Rachel Armstrong, a lead researcher on Project Persephone, hopes to develop synthetic soils optimised to support life and recycle waste: "it's all very fine to conserve energy and be considerate about polluting the environment, but is that actually sustainable? We want to build sustainable environments that promote life" (Sample, 2014). Space refugia tend to be increasingly considered as part of Plan C, as plan A (cutting greenhouse gas emissions) and plan B (geoengineering) become more and more unlikely: in 2012, the US launched the 100 Year Starship, an ambitious project funded by NASA and the government's Defence Advanced Research Projects Agency (DARPA), to explore technologies needed to make intergenerational, interstellar space travel a reality a century from now (Hamilton, 2014). Consider the mission statement of the Space Frontier Foundation, an aerospace lobby which has successfully lobbied the US government for the increasing privatisation of its 
space programs: "Given the fragility of our planet, we also believe that it is vital that we not only preserve the biosphere of earth using the resources of space, but that we expand that biosphere, taking life to worlds now dead" (Tumlinson, 2003). In apparent contravention of the 1967 UN Outer Space Treaty which declares space the common heritage of mankind, and expressly forbids sovereign claims, the US Congress passed in 2015 the US Commercial Space Launch Competitiveness Act (H.R. 2262), affirming the private property rights of US citizens over space resources, for the benefit of private firms working toward off-earth mining ventures. ${ }^{6}$

Thorpe has argued that "the trajectory of capitalist technology is toward artificial life on a dead planet" (2013: 2). Evoking the possibility that a tiny elite may escape the dying Earth (and the rest of us, presumably left to our fates), MELiSSA emboldens the utopian anticipation of a synthetic biosphere within which the privileged may continue to elude the earthly consequences of their history. At the heart of this "impure" politics of anticipation lies an inextinguishable "dream of wasteless production" and limitless technological expansion, in which new technologies will allow us eventually to consume without laying waste, "opening up new possibilities of guiltless consumption and abundance" (Schwarz, 2009, p. 139). If the Space Frontier Foundation dreams of a 'New Space', a free-market frontier where the unsupervised exploitation of space resources occurs in a zero-gravity and zero-tax environment, MELiSSA's futures are perhaps more European in character, promoting multi-national co-operation to build eco-technologies which will aid in the transition to a 'knowledge based bio-economy', re-integrated into Earth flows via hyperefficient waste recycling technologies. ${ }^{7}$ Both dream of an endless abundance of resources and space.

What would be the price to pay for a guiltless abundance achieved through the ideal recycling of the totality of our waste? The futures of MELiSSA are about engineering both a minimal biosphere and a minimal human being - who tellingly is a human-within-abiosphere. If Slotjerdijk invokes our vital embeddedness in existential bubbles - from mothers' womb to the whole biosphere - here the vital connection to life sustaining bubbles discloses a state of total technological dependence. The architect Lydia Kallipoliti (2008) describes the design of self-sustaining habitats in terms of the co-transformation of architecture and human body by means of "a dissolution of the human body within the elements of the system through retroactive loops and material connections". Rather than being freed from domination, self-sustaining architecture and the minimal human body are inexorably bound to each other for survival - constantly threatened by the possibility of contamination, malfunction and death.

Similarly, MELiSSA suggests that we will not be left alone with our technoscientific creations, including our most "ecological" life-sustaining artifacts. Even those who dream of escaping the piling up of our waste on Earth must reckon with their dependence on the labour of invisible others, companion species able to regenerate the world by building communities of life from human-generated wastes. Which might be good news after all.

\section{Acknowledgements}

We thank the manager of ESA'S MELiSSA project and the lead researcher of the MELiSSA pilot plant for their time: interviews with them and a visit to the MELiSSA pilot plant were most precious resources for our research. We would not claim endorsement:

\footnotetext{
${ }^{6}$ We are indebted to Matt Johnson for this reference, and the important insights raised by his doctoral research at UTS into the anticipatory fortification of private property claims in space.

${ }^{7}$ On the role of industrial microbiology in the anticipated transition to a post-petrochemical bioeconomy, see Walker (2016).
} 
interpretations of these data and any errors remain ours alone. We acknowledge support for our field-work: Jeremy Walker benefitted from an Embassy of France Office of Science and Technology Travel Scholarship, Céline Granjou from an AGIR-POLE 2016 research grant (Ecofuturs).

\section{References}

Abrahamsson, S., \& Bertoni F. (2014). Compost politics: experimenting with togetherness in vermicomposting. Environmental Humanities, 4, 125-148.

Akkermans, T., Thiery, W., \& Van Lipzig, N. P. (2014). The regional climate impact of a realistic future deforestation scenario in the Congo Basin. Journal of Climate, 27(7), 2714-2734. 239-268.

Anker, P. (2005). The ecological colonisation of space. Environmental History, 10,

Anderson, W. (1995). Excremental colonialism: public health and the poetics of pollution. Critical Inquiry, 21(3), 640-669.

Appadurai, A. (2001). Deep democracy: urban governmentality and the horizon of politics, Environment and Urbanisation, 13(2), 23-43.

Bateson, G. (1973) Steps to an ecology of mind. London: Paladin.

Baum, S. D., Denkenberger, D.C., Haqq-Misra, J. (2015). Isolated refuges for surviving global catastrophes. Futures, 72, 45-56.

Boulding K. (1966). The economics of the coming Spaceship Earth. In H. Jarrett (Ed.), Environmental quality in a growing economy (pp. 3-14). Baltimore: Johns Hopkins University Press.

Butler, J. ([1990] 2010) Gender trouble. Oxon: Routledge.

Fischer-Kowalski, M. \& Hüttler, W. (1998). Society's metabolism. Journal of Industrial Ecology, 2(4), 107-136.

Foster, J. B., \& Magdoff, F. (1998). Liebig, Marx, and the depletion of soil fertility, relevance for today's agriculture. Monthly Review 50(3).

Gandy, M. (2014). The fabric of space: water, modernity and the urban imagination. Cambridge: MIT Press.

Garland, J. I. (2007). Microbial functions in space: Mars transit to early planetary base exploration missions, Acta Astronautica 60, 518-524.

Godia, F., Albiol, J., Montesinos, J.L., Perez, J., Creus, N., Cabello, F., Mengual, X., Montras, A., \& Lasseur, C. (2002). MELISSA: a loop of interconnected bioreactors to develop life support in Space. Journal of Biotechnology, 99, 319-330.

Granjou, C. \& Walker J. (2016). Promises that matter: reconfiguring ecology in the ecotrons. Science and Technology Studies, 29(3), 49-67.

Hamilton, C. (2014). Can humans survive the Anthropocene? Lecture to the Sydney Writer's Festival, 22 May 2014. http://clivehamilton.com/can-humans-survivethe-anthropocene

Hari, J. (2006). Congo's tragedy: the war the world forgot'. The Independent, 5 May 2006. http://www.independent.co.uk/news/world/africa/congos-tragedy-the-warthe-world-forgot-6101835.html

Hendrickx, L. \& Mergeay, M., (2007). From the deep sea to the stars: human life support through minimal communities. Current Opinion in Microbiology 10, 231-237.

Hendrickx, L., de Wever, H., Hermans, V., Mastroleo, F., Morin, N., Wilmotte, A., Janssen Janssen, P., \& Mergeay, M. (2006). Microbial ecology of the closed artificial ecosystem MELiSSA (Micro-Ecological Life Support System Alternative): reinventing and compartmentalising the Earth's food and oxygen regeneration for long-haul space exploration missions. Research in Microbiology, 157, 77-86.

Hird, M. (2009). The origins of sociable life: evolution after science studies. New York: Palgrave.

Höhler, S. (2014). Spaceship Earth in the environmental age, 1960-1990. New York: Routledge.

Kallipoliti, L. (2008). Feedback man. $\log 13 / 14,1-4$. 
Kohlmaier, G., \& Von Sartory, B. (1986). Houses of glass. Trans. John C. Harvey. Cambridge, MA: MIT Press.

Laporte, D. ([1978] 2002). History of shit. Cambridge: MIT Press.

Lasseur, C. Verstraete, W., Gros, J. B., Dubertret, G., \& Rogalla, F. (1996). MELISSA: a potential experiment for a precursor mission to the moon. Advances in Space Research, 18, 11111-11117.

Liebig, J. (1852). Agricultural chemistry. Philadelphia: TB Peterson.

Meadows, D. H., Meadows, D. L., Randers, J., \& Behrens, W. W., (1972). The limits to growth. Universe Books.

Menezes A. O., Cumbers, J., Hogan J. O. \& Arkin, A. P. (2015). Towards synthetic biological approaches to resource utilisation on space missions. Journal of the Royal Society: Interface, 12(102), 20140715.

Mergeay, M., Verstraete, W., Dubertret, G., Lefort-Tran, M., Chipaux, C., \& Binot, R. (1988). MELiSSA: A micro-organisms-based model for CELSS development. In ESA, Third European Symposium on Space Thermal Control and Life Support Systems, 65-68.

Montague, D. (2002). Stolen goods: coltan and conflict in the Democratic Republic of Congo. SAIS Review, 22(1), 103-118.

National Institute of Health (2012) NIH Human Microbiome Project defines normal bacterial makeup of the body. 12 June 2012. http://www.nih.gov/news-events/newsreleases/nih-human-microbiome-project-defines-normal-bacterial-makeup-body

O'Neill, G.(1976). The high frontier: human colonies in space. New York: William Morrow.

Paradiso, R., De Micco, V., Buonomo, R., Aronne, G., \& De Pascale S. (2014). Soilless cultivation of soybean for bioregenerative life-support systems: a literature review and the experience of the MELiSSA Project. Plant Biology 16, 69-78.

Pougetoux, A. (2012). The hothouse at Malmaison (multimedia), National Gallery of Victoria: www.ngv.vic.gov.au

Puig de la Bellacasa, M. (2013). Encountering bioinfrastructure : ecological struggles and the sciences of soil. Social Epistemology, 28(1), 26-40.

Saito, K. (2014). The emergence of Marx's critique of modern agriculture. Monthly Review, 66(5).

Sample, I. (2014) Stars in their eyes: architects and scientists mull designs for ark in space. The Guardian, 22 May 2014.

Simon, J. L. (1989). The ultimate resource 2. Princeton, NJ: Princeton University Press.

Solow, R. M. ([1974] 2000). The economics of resources or the resources of economics? In Gopalakrishnan, C. (Ed.), Classic papers in natural resource economics (pp. 257-276). London: Palgrave Macmillan.

Schwarz, A. (2009). Escaping from limits to visions of space. In A. Ferrari, \& S. Gammel, (Eds.), Visionen der Nanotechnologie (pp. 129-142). Berlin: Akademische Verlagsgesellschaft.

Sloterdijk, P. (2013) In the world interior of capital: towards a philosophical theory of globalisation. Cambridge: Polity.

Thorpe, C. (2013) Artificial life on a dead planet. In Gates K. (Ed.), The International Encyclopedia of Media Studies, Vol. V. Oxford: Blackwell.

Tumlinson, R. (2003). Testimony of Rick Tumlinson, Space Frontier Founder, before the Senate Committee on Commerce, Science and Transportation, 30 Oct 2003. http://history.nasa.gov/

Walker, J. (2016). The creation to come: pre-empting the evolution of the bioeconomy. In Marshall, J. \& Connor, L. (Eds.), Environmental change and the world's futures: ecologies, ontologies and mythologies (pp. 264-281). Sydney: Routledge.

Wilson, K. (2010). Justus van Liebig and the birth of modern biochar. Journal für Terroirwein und Biodiversität. http://www.ithaka-journal.net/english-justus-von-liebigand-the-birth-of-modern-biochar 